\title{
The evaluation of treatment difficulty in orthognathic surgery
}

\author{
Sejin Han, DDS, MSD, PhD \\ Section Editor of JKAOMS \\ Department of Oral and Maxillofacial Surgery, College of Dentistry, Dankook University, Cheonan, Korea
}

Assessment of the difficulty of a surgical procedure in oral and maxillofacial surgery is an important consideration. From the viewpoint of an oral and maxillofacial surgeon, stress is directly proportional to the difficulty of treatment. Furthermore, the more difficult is the surgical procedure, the more likely it is that complications will follow. Therefore, patients must be informed about the difficulty of surgery prior to consent. Also, the treatment cost in the health insurance system can be affected by the difficulty of the procedure.

Surgical removal of the third molar is one of the most common surgical procedures in oral and maxillofacial surgery and has been the topic of a number of previous studies ${ }^{1}$. Pederson has proposed a difficulty index for removal of the impacted mandibular third molar. The difficulty score is judged on the basis of radiographic factors of angulations, depth, and ramus relationship ${ }^{2}$. The Pederson index, cited in the textbooks of oral and maxillofacial surgery, is simple and efficient but is limited by the requirement for radiologic assessment. Most surgeons state the limitation of estimating surgical difficulty based only on radiologic methods, and that actual difficulty only can be estimated intraoperatively. Some surgeons believe that clinical variables, such as patient age, gender, and weight, are very important ${ }^{3}$.

The evaluation of treatment difficulty in orthognathic surgery is more challenging than in extraction of impacted third molars because orthognathic surgery involves more complex treatment plans and more patient variables. Rather than for prevention or treatment of disease, combined orthodontic-

\section{Sejin Han}

Department of Oral and Maxillofacial Surgery, College of Dentistry, Dankook University, 119 Dandae-ro, Dongnam-gu, Cheonan 31116, Korea

TEL: +82-41-550-3079

E-mail:hanimplant@dankook.ac.kr

ORCID: https://orcid.org/0000-0003-4949-4462

(c) This is an open-access article distributed under the terms of the Creative Commons Attribution Non-Commercial License (http://creativecommons.org/ licenses/by-nc/4.0/), which permits unrestricted non-commercial use, distribution, and reproduction in any medium, provided the original work is properly cited.

Copyright (C) 2021 The Korean Association of Oral and Maxillofacial Surgeons. orthognathic surgical treatment usually is undertaken at the request of the patient to improve aesthetics or function. As such, surgeons need to be able to explain the difficulty of orthognathic surgery to both the patient and the orthodontist on a case-by-case basis ${ }^{4}$. Although not easy, successful outcomes in orthognathic surgery include satisfaction of the patient, orthodontist, and surgeon.

Oral and maxillofacial surgeons face a series of difficulties in orthognathic surgery. Classically, surgeons analyze patient cephalometric radiography and plan the orthognathic surgery. Surgeon and orthodontist communicate with each other in basis of paper surgery. Expert surgeons can predict treatment difficulty in this step, but two-dimensional (2D) analysis has limitations for evaluation. These days, three-dimensional (3D) analysis and simulation are used to advise treatment planning, but soft tissue changes are yet to be predicted correctly. It is important that surgeons adequately explain the limitations of 3D simulation to the orthodontist and the patient. In addition, cast model surgery for constructing the surgical stent involves time-consuming laboratory work that often requires aid from as assistant. The more complicated is the treatment plan, the more difficult is this work.

Surgeon face predicted and/or unpredicted intra-operative difficulties in orthognathic surgery. Intra-operative difficulties can be predicted from radiographic analysis, 3D simulation, and model surgery. A large amount of mandibular and maxilla movement, multiple osteotomy lines, severe facial asymmetry, unstable occlusion, and a preexisting defect in anatomical structure increase the difficulty of orthognathic surgery. Unpredicted intra-operative difficulties include unfavorable bone osteotomy, incorrect surgical stent, inadequate condyle positioning, severe bleeding, and nerve damage. All of these are related to surgeon skill and patient anatomy.

In evaluating treatment difficulty in orthognathic surgery, the surgeon considers three factors: stability of occlusion, combined soft tissue and other structural problems, and pa- 
tient factors such as other disease or psychosocial problem. Unstable occlusion complicates treatment, as does a status of first orthognathic surgery. In such cases, communication between the surgeon and orthodontist particularly are important.

The causes of facial asymmetry are varied and can result from skeletal problem, soft tissue problem, or both. When treatment with orthognathic surgery is insufficient, the surgeon must consider adjunctive facial surgery, such as genioplasty, mandibular angle contouring, lateral corticectomy of the mandible, zygoma reduction or augmentation, rhinoplasty, paranasal augmentation, or fat graft. Orthognathic surgery is required in $25 \%$ of patients with cleft lip and palate (CLP) for correction of dentofacial deformity ${ }^{5}$. Surgical procedures for patients with CLP are more difficult than for those without because of scarring, insufficient soft tissue, and oronasal fistula ${ }^{6}$. In addition, patient medical problems, age, or psychosocial problems can make treatment more difficult.

Although an expert surgeon can attempt to predict surgical difficulty from radiographic analysis, 3D simulation, and model surgery, it is complicated by the wide variation among factors. Nevertheless, systematic and computerized assessment of treatment difficulty in orthognathic surgery via additional research and scientific data will help the oral and maxillofacial surgeon to achieve a successful surgical outcome.

\section{Conflict of Interest}

No potential conflict of interest relevant to this article was reported.

\section{References}

1. Renton T, Smeeton N, McGurk M. Factors predictive of difficulty of mandibular third molar surgery. Br Dent J 2001;190:607-10. https://doi.org/10.1038/sj.bdj.4801052

2. Pederson GW. Surgical removal of tooth. In: Pedersen GW, ed. Oral Surgery. Philadelphia: Saunders; 1988.

3. Gbotolorun OM, Arotiba GT, Ladeinde AL. Assessment of factors associated with surgical difficulty in impacted mandibular third molar extraction. J Oral Maxillofac Surg 2007;65:1977-83. https:// doi.org/10.1016/j.joms.2006.11.030

4. Williams AC, Shah H, Sandy JR, Travess HC. Patients' motivations for treatment and their experiences of orthodontic preparation for orthognathic surgery. J Orthod 2005;32:191-202. https://doi. org/10.1179/146531205225021096

5. Ross RB. Treatment variables affecting facial growth in complete unilateral cleft lip and palate. Cleft Palate J 1987;24:5-77.

6. Hwang DS, Choi HS, Kim UK, Song JM. Complications following orthognathic surgery for patients with cleft lip/palate. J Craniofac Surg 2019;30:1815-9. https://doi.org/10.1097/ SCS.0000000000005536

How to cite this article: Han S. The evaluation of treatment difficulty in orthognathic surgery. J Korean Assoc Oral Maxillofac Surg 2021;47:339-340. https://doi.org/10.5125/jkaoms.2021.47.5.339 